\title{
SOME CONSIDERATIONS ON THE KEY FACTORS DETERMINING THE REDUCTION OF PUBLIC TRANSPORT DEMAND IN SICILY DURING COVID-19 PANDEMIC
}

\author{
TIZIANA CAMPISI ${ }^{1}$, SOCRATES BASBAS $^{2}$, NURTEN AKGÜN TANBAY ${ }^{3}$ \& GEORGIOS GEORGIADIS $^{4}$ \\ ${ }^{1}$ University of Enna Kore, Faculty of Engineering and Architecture, Cittadella Universitaria, Italy \\ ${ }^{2}$ School of Rural \& Surveying Engineering, Faculty of Engineering, Aristotle University of Thessaloniki, \\ Thessaloniki, Greece \\ ${ }^{3}$ Department of Civil Engineering, Faculty of Engineering and Natural Sciences, Bursa Technical University, \\ Turkey \\ ${ }^{4}$ School of Civil Engineering, Faculty of Engineering, Aristotle University of Thessaloniki, Thessaloniki, Greece
}

\begin{abstract}
The development of transport services and infrastructures strongly depends on the characterization of the different types of road users who travel daily from one place to another for a specific purpose. In the case of a public transport (PT) system, it is essential to understand the dynamics of passenger choices in order to optimize the use of the service provided (e.g. location of stops, frequency of service, departure and arrival times of bus lines). The recent COVID-19 pandemic has led to the implementation of a number of measures, both by governments (such as social distancing) and by PT agencies (such as limiting the number of passengers on board), which have influenced the propensity to use this transport mode. Since May 2020, there has been an increase in the number of vehicles in circulation in Sicily, Italy, after the lockdown phase, which has clearly led to an interesting study of emerging behaviours and habits among different people. This paper attempts to identify the factors that led to reduced PT demand in Sicily after the lockdown period. Empirical findings indicated that the decrease of scheduled PT services, the limitations on the maximum people on board, the general fear of COVID-19 infection and the failure of PT system to properly adapt to the modified business hour environment have been important PT-discouraging factors in Sicily. These findings were not significantly differentiated among the various sociodemographic groups of travellers. This research can provide valuable knowledge for the optimization of urban and intercity PT services under extreme conditions such as the COVID-19 pandemic. It may also favour the diffusion of sustainable mobility strategies and disincentivize the use of the private car while also improving road safety and environmental cleanliness in urban and interurban space.
\end{abstract}

Keywords: COVID-19, Italy, mobility factors, public transport, social distancing, sustainable mobility, travel behaviour, travel preferences.

\section{INTRODUCTION}

The recent pandemic has changed global mobility. Several strategies have been implemented by European governments to reduce possible contagions. These strategies have stimulated, on the one hand, a reduction in travel with a decrease in emissions from vehicular traffic but, on the other hand, have encouraged the use of private vehicles immediately after the lockdown phase. In the research literature, there are several studies that have analysed the variation of mobility during the different pandemic phases both classifying the best and the worst transport choices according to the users' judgement [1] and also through studies that have considered which strategies should be promoted in post-pandemic cities in order to mitigate possible impacts [2-3] and ensure the development of the concept of sustainable mobility [4]. Various strategies have been implemented that have aimed at respecting social distancing and reducing the gathering of more people. 
Not only have public transport (PT) agencies reduced the maximum number of users on board but also companies and local authorities have implemented strategies such as teleworking and limiting exit times (in many European countries until 22:00). The implementation of differentiated working hours with wide windows of beginning and ending of working activities has been necessary to modulate the mobility of commuters and consequently prevent the risks of aggregation related to the mobility of citizens [5-6].

The differentiation and extension of the opening hours of offices, shops, public services and schools of all levels were also necessary. At a European level, actions have been activated to encourage sustainable mobility (bicycles, e-bikes, etc.) and to plan new infrastructures in order to encourage individual movements and discourage the use of private vehicles [7-9]. These measures have been modulated in relation to the needs of the territory and the catchment area of reference. They have initially promoted the reduction of peaks in the use of collective PT present in the period before the health emergency and lockdown. The individual responsibility of all users of PT services has been defined as an essential point to ensure interpersonal distancing or, in any case, for the maintenance of correct behaviour [10]. In addition, a clear and simple communication in every context (railway stations, subways, airports, bus stations, means of transport, etc.) through signs and mobile information panels has been an essential instrument to communicate the necessary behavioural rules in the use of transport. PT was one of the sectors most affected by economic losses not only because of the restrictions that reduced the number of users but also because of the rampant fear that users had of possible contagion inside vehicles [11-12].

In this paper, we are dealing with the case study of Sicily, which was among the regions of Italy that was most affected by the pandemic both in terms of COVID-19 cases and travel behaviour modifications [13]. From the analysis conducted through the dissemination of a questionnaire addressed to regular PT users, we are demonstrating the factors that deterred them from using PT during the pandemic; also, we highlight the role of their profile characteristics in their perceptions regarding such PT-discouraging factors. The study assists in recognizing some criticalities that lay the foundations for the improvement of the PT services in the coming months.

The remainder of the paper is as follows. The next section provides important information on the PT trends and measures that were observed in Italy and Sicily during the COVID19 crisis. The third section explains the questionnaire survey of this study and presents the variables that describe the profile and PT demand characteristics of the respondents, as well as the PT-discouraging factors that were investigated. In the same section, we present the analysis setting we employed to reach the aims of our study. The results of our analyses are presented and discussed in the fourth section, and the conclusions are summarized in the last (fifth) section.

\section{BACKGROUND}

\subsection{COVID-19 impact on PT demand in Italy}

The post-pandemic PT demand trend was characterized by a substantial change in transport mode choice [14]. A study conducted in Italy for the definition of the index for mobility (https://moovitapp.com/), via the dissemination of an anonymized survey and aggregate data analysis during March-December 2020, has highlighted that $12 \%$ to $20.3 \%$ of commuters stopped using PT, while $41.4 \%$ to $44.1 \%$ of them reduced their PT trips (Figure 1). 


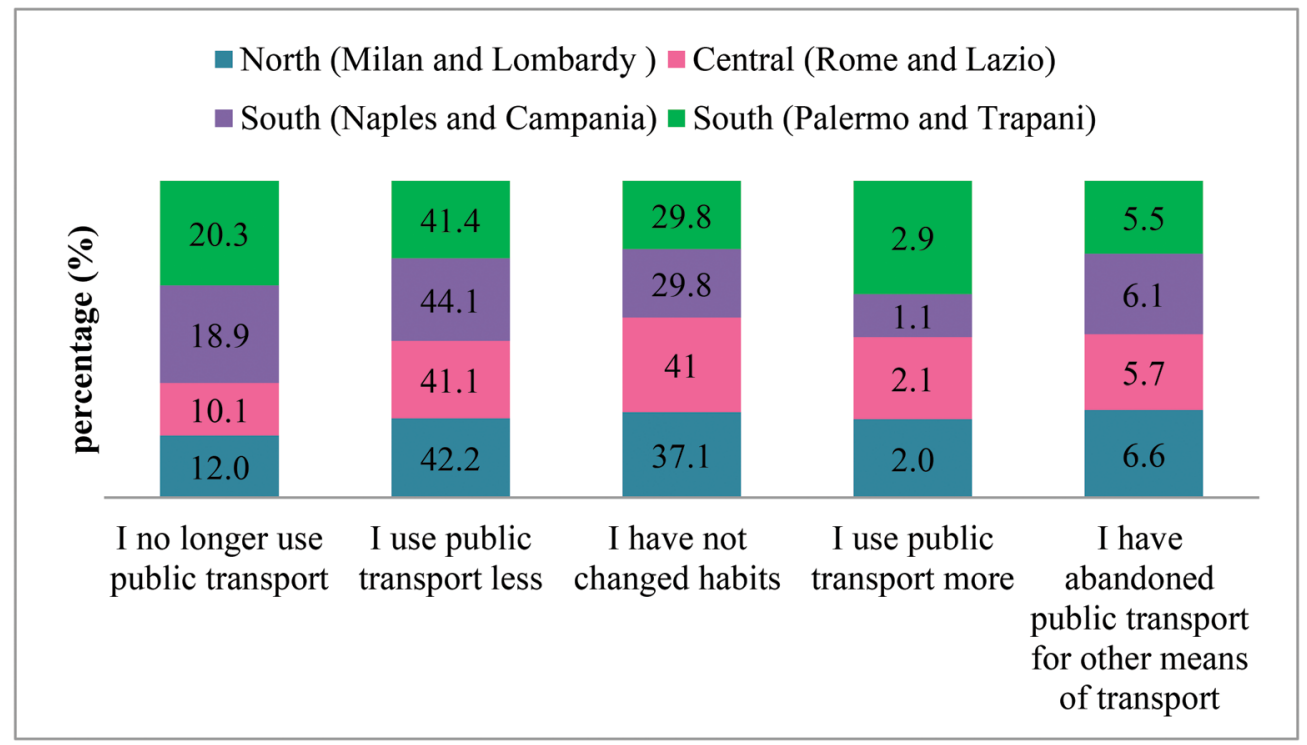

Figure 1: How has the pandemic changed the way you get around? Value in percentage (\%) for different areas of Italy (Source: https://moovitapp.com/).

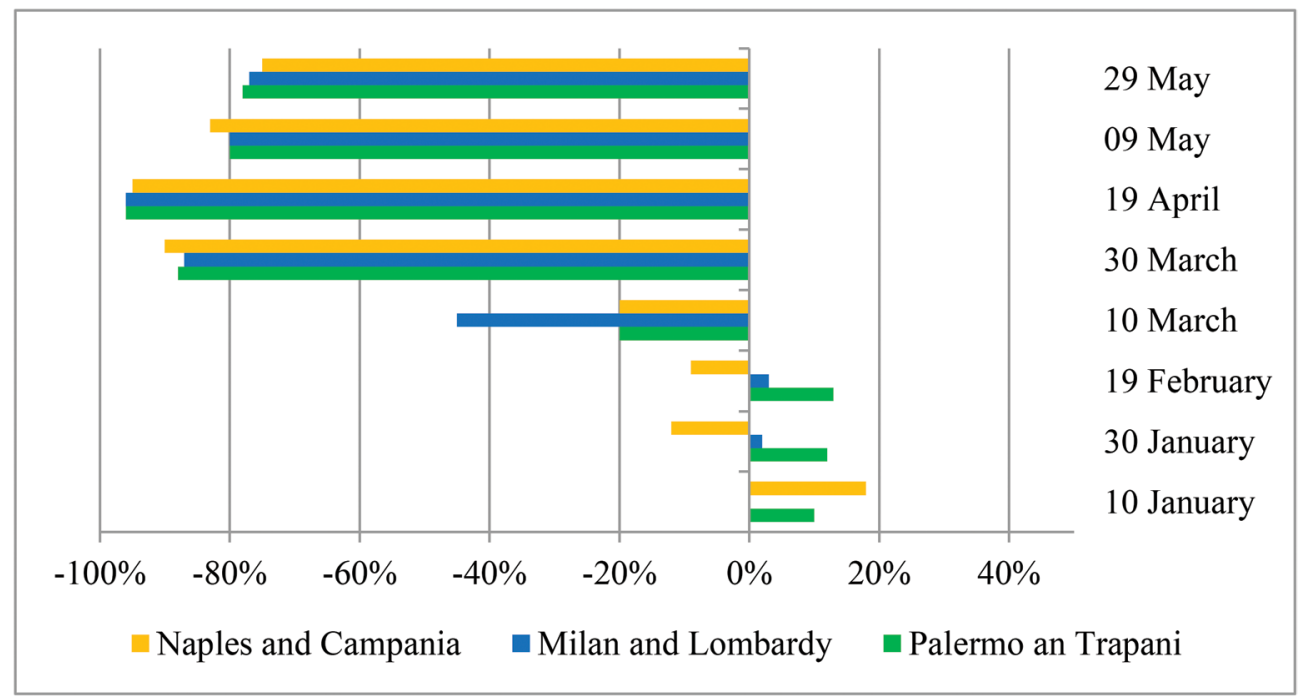

Figure 2: The trend of public transport use in some Italian regions starting from January 2020 until the end of the lockdown (May 2020) (data source: https://moovitapp.com/).

The greatest changes in modal choice have been recorded in the regions of Southern Italy compared to the other regions. The decrease in PT use during working days showed a substantial reduction of $20 \%$ nationally and similarly in Sicily from the January to March 2020 period of pandemic spread [1]. 
After the date of 8 March 2020, there has been a reduction of almost 100\% until May 2020 due to the lockdown travel restrictions. Comparing the data from Southern Italy represented by Palermo and Trapani (for Sicily) and Naples and Province (for Campania) with the data from Milan and Lombardy (first area of infections and deaths from COVID-19 in Italy) in Figure 2, it is possible to observe such modal behaviour change. This severe PT demand reduction may also be attributed to the reduced number of modal choices (e.g. absence of high-speed trains and reduced presence of subways) in Southern Italy.

\subsection{Response measures for safeguarding PT use in Italy and Europe}

The Italian Government has issued documents containing both general measures for the containment of COVID-19 infection and recommendations related to the use of different forms of PT. The general measures have considered the sanitization and hygiene [15], transport system and scheduling work [16]. While entering and staying in PT access points (railway stations, bus stations, bus stops, airports, ports and long-distance vehicles), it was necessary to install dispensers containing disinfectant solutions for use by passengers. On board PT vehicles, it has been made compulsory to wear a community mask to protect the nose and mouth [17]. Finally, the sale of tickets using electronic systems has been encouraged [18-21]. In the case of PT, the following actions have also been implemented:

- Separation of boarding and alighting movements of PT passengers through the designation of "only boarding" or "only alighting" vehicles' doors"

- Application of markers on seats that cannot be used on board surface vehicles and subway trains

- Increase in the frequency of vehicles at times when there is high flow of passengers

- Reduced capacity of vehicles with a maximum number of passengers to allow compliance with the 1-m distance

- Video surveillance equipment and/or smart cameras to monitor flows and avoid crowds

- Suspension of the sale and control of tickets on board.

These measures have gradually been accepted by PT users, although few problems related to socio-economic issues or habits of using electronic tools have occurred, especially among the elderly. In addition, some of the regions, especially in large cities, have become areas of weak demand, and they were often without PT services. These critical limitations have significantly encouraged people to use private cars.

Meanwhile, the EU member states have been using digital passenger tracking modules to collect data on cross-border travellers entering their territory, and, in public air transport, sector-specific measures have been defined for the legal conditions necessary for processing such personal data. Several restrictions have been implemented by several European and non-European countries related to security and especially to social distancing, frequent hand washing and surface cleaning [22-25]. The Policy Learning Platform [26] collected about 20 good practices related to COVID-19 and PT and devised a typology of measures that can be introduced and summarized in the following six points:

1) Increase transport capacity by increasing the number of buses and trains in circulation, as in Madrid and Dublin, so that people can travel while maintaining social distancing [27-28]. 
2) Restricting rides to certain users only, such as the buses and trams dedicated to vulnerable people, implemented in Iasi (Romania) and Auckland, New Zealand, to provide transport services only to those who really need them [29-30].

3) Shifting demand away from peak hours, as has been done with businesses in France and schools in the Netherlands, by encouraging people to spread out their journeys so that not everyone tries to travel at the same time during peak hours [31-32].

4) Helping riders to make choices that alleviate crowding by providing information on crowding. This is mainly done through websites and apps.

5) Promoting safety measures such as compulsory wearing of masks, frequent cleaning and on-board information. This includes the free distribution of masks in Madrid, travel guidelines in Ireland and the UK.

6) Restoring confidence through communication and public relation measures, such as free train tickets offered in Belgium to encourage people to return to their normal routines.

The above six measures are closely related to the ones that the Italian government has introduced at the national level to limit infections in PT systems. The present research aims to understand how the Italian governmental strategies and recommendations have influenced people's propensity to use PT. Therefore, the actual application of the recommendations and main measures implemented in Italy was considered when defining the set of factors that were examined as potential reasons for the decreased PT demand during the periods following the COVID-19 lockdown in Sicily.

\section{MATERIALS AND METHODS}

\subsection{Data overview}

We designed and launched a customized online questionnaire survey on the Google platform to collect data from residents of Sicily who frequently used local or/and regional bus PT services to travel for work and/or for other purposes before the COVID-19 pandemic. The survey was disseminated by Facebook and WhatsApp pages during the period of OctoberDecember 2020. A total of 700 completed questionnaires were collected.

The questionnaire included multiple choice and Likert-scale questions that collected information regarding:

- Sociodemographic and socioeconomic characteristics of the respondents.

- Trip frequency rates with local and regional bus PT services for the periods: (a) before the COVID-19 pandemic, (b) after the COVID-19 lockdown (May-September 2020) and (c) Phase II period between October and December 2020.

- The factors that respondents consider as the most important reasons for avoiding or decreasing local and regional bus PT use during the post-lockdown and Phase II periods.

For the latter case, the respondents were asked to select the three most important factors, and rank them in order of importance, out of a predetermined list of ten factors, which appears in Table 1. These factors have been defined considering a period of analysis of Sicilian PT in the pre-pandemic phase, especially during peak demand hours in the major cities of the island. Therefore, taking into consideration what happened before the pandemic 
and the measures defined by the governmental regulations, three different types of factors have been considered, namely:

- factors analysed by monitoring some bus stops before the pandemic,

- factors transmitted through the mass media,

- factors related to government restrictive measures.

From the review of images and surveys conducted in December 2019 through the monitoring of bus stops, special attention was paid to the events of overloading of the vehicles, hygiene and the decrease of scheduled services (due to strikes or accidents). The other factors considered were selected taking into account what happened during the pandemic phase and communicated by the major information channels, such as the probability of contracting infections on board or misleading information provided by the mass media (factors titled D and E). Finally, the third category includes factors from F to I. Factor J (Other) pertains to issues such as the behaviour of users on board, delays in the transport service, the absence of appropriate signs on board etc.

Table 2 shows the PT trip frequency characteristics of the sample before and after the COVID-19 pandemic. The respondents have been very frequent PT commuters by local or regional bus services (92.0\% and $92.4 \%$, respectively) before the pandemic. After lockdown and during Phase II, these frequency rates have been dramatically reduced, since almost half of them stopped using local PT services (46.9\% and 41.6\%) and regional PT services (45.9\% and $41.3 \%$ ) for home-based work trips. Similar frequency trends also apply for the other travel purposes. Specifically, for Phase II, the vast majority of the respondents discontinued the use of local $(82.3 \%)$ and regional $(84.1 \%)$ PT for making non-commuting trips. Thus, the sample of respondents includes both workers who were unable to use teleworking but continued to commute by PT, as well as workers who might have shifted to teleworking or temporarily have been off from work.

Table 3 shows that the 700 respondents were almost equally grouped into men (43.7\%) and women $(56.3 \%)$. The age groups of 22-25 (33.6\%) and 26-30 (39.4\%) concentrate the most

Table 1: Factors examined to explain the reduced PT demand in Sicily after lockdown and during Phase II of the COVID-19 pandemic.

\begin{tabular}{ll}
\hline$\#$ & Description of Factors \\
\hline A & Excess of maximum recommended capacity in PT buses \\
B & Inadequate sanitation of passenger cabins and stops/stations \\
C & Decrease of PT scheduled services \\
D & Higher possibility of COVID-19 infection during PT use \\
E & Misleading or controversial mass media information \\
F & Suggestions to prefer e-ticketing rather than paper tickets and purchasing on board \\
G & Inadequate or out-of-date information for PT services \\
H & General restrictions on PT services imposed by PT agencies (i.e., seating restriction) \\
I & Modified business/working hours or/and teleworking \\
J & Other \\
\hline
\end{tabular}


Table 2: Table 2PT trip frequency characteristics of the sample.

\begin{tabular}{|c|c|c|c|c|}
\hline \multirow{2}{*}{ PT Use Variables } & \multirow{2}{*}{ Frequency Rates } & \multicolumn{3}{|c|}{ Time-period } \\
\hline & & Before Pandemic & After Lockdown & Phase II \\
\hline \multirow{3}{*}{$\begin{array}{l}\text { Local Bus for } \\
\text { Home-Based Work } \\
\text { Purposes }\end{array}$} & No use & $0.0 \%$ & $46.9 \%$ & $41.6 \%$ \\
\hline & $\begin{array}{l}\text { More than } 1 \text { times } \\
\text { per week }\end{array}$ & $8.0 \%$ & $43.3 \%$ & $44.4 \%$ \\
\hline & Daily or more & $92.0 \%$ & $9.8 \%$ & $14.0 \%$ \\
\hline \multirow{3}{*}{$\begin{array}{l}\text { Local Bus for } \\
\text { Home-Based Other } \\
\text { Purposes }\end{array}$} & No use & $2.1 \%$ & $42.9 \%$ & $82.3 \%$ \\
\hline & $\begin{array}{l}\text { More than } 1 \text { times } \\
\text { per week }\end{array}$ & $19.3 \%$ & $43.8 \%$ & $10.7 \%$ \\
\hline & Daily or more & $78.6 \%$ & $13.3 \%$ & $7.0 \%$ \\
\hline \multirow{3}{*}{$\begin{array}{l}\text { Regional Bus for } \\
\text { Home-Based Work } \\
\text { Purposes }\end{array}$} & No use & $0.0 \%$ & $45.9 \%$ & $41.3 \%$ \\
\hline & $\begin{array}{l}\text { More than } 1 \text { times } \\
\text { per week }\end{array}$ & $7.6 \%$ & $42.2 \%$ & $44.8 \%$ \\
\hline & Daily or more & $92.4 \%$ & $11.9 \%$ & $13.9 \%$ \\
\hline \multirow{3}{*}{$\begin{array}{l}\text { Regional Bus for } \\
\text { Home-Based Other } \\
\text { Purposes }\end{array}$} & No use & $2.1 \%$ & $44.0 \%$ & $84.1 \%$ \\
\hline & $\begin{array}{l}\text { More than } 1 \text { times } \\
\text { per week }\end{array}$ & $17.0 \%$ & $42.7 \%$ & $8.5 \%$ \\
\hline & Daily or more & $80.9 \%$ & $13.3 \%$ & $7.4 \%$ \\
\hline
\end{tabular}

Table 3: Profile characteristics of the sample.

\begin{tabular}{ll}
\hline Characteristics of the Participants & Units and Percentages \\
\hline Gender & Male $(43.7 \%)$; Female $(56.3 \%)$ \\
& $18-21(5.3 \%) ; 22-25(33.6 \%) ; 26-30(39.4 \%) ;$ \\
Age Groups & $31-35(17 \%) ; 36-40(3.3 \%) ;>40$ years old $(1.4 \%)$ \\
& Freelancer $(14.7 \%) ;$ Employee $(59.7 \%)$; Other \\
Occupation & $(25.6 \%)$ \\
& Small town $(18.4 \%) ;$ Town $(28.3 \%)$; City $(33.4 \%) ;$ \\
Residential Area & Metropolis $(19.9 \%)$ \\
Household Monthly Income & $<1,000$ euros $(25.1 \%) ; 1,001-1,500$ euros $(31.6 \%) ;$ \\
& $1,501-2,000$ euros $(26.1 \%) ;>2,000$ euros $(17.1 \%)$ \\
\hline
\end{tabular}

observations, while a much smaller percentage of people over 40 years old (1.4\%) participated in the survey. This is probably due to the on-line character of the survey and the fewer digital competencies among older age groups [21]. In fact, the COVID-19 restrictions did not provide us with the possibility of carrying out face-to-face interviews reducing some population groups with low technological operability (e.g. the elderly). During the next steps of analysis, other population groups will be investigated (e.g. children and the elderly). Employees constitute $60 \%$ of the respondents and the remaining ones are shared between freelancers 
(14.7\%) and other types of employment (25.6\%). In addition, the sample of respondents is nicely distributed across the different types of residential areas. Finally, most of the respondents belong to low- or medium-income groups of up to 2,000 euros per month.

\subsection{Analysis setting}

In this study, we used descriptive statistics to determine and evaluate the level of importance that was attributed by the respondents to each of the ten PT-deterring factors of Table 1. In order to determine whether each of the ten factors had a critical importance towards using PT in Sicily, we considered the percentages of respondents who included them in their top-3 most important list. We performed the same analysis for each of the two examined periods, i.e. after lockdown and Phase II, separately, so as to monitor any differentiations over travellers' perceptions and preferences.

Furthermore, we used inferential statistical techniques to investigate whether the importance of critical factors is associated with certain profile characteristics or PT travel frequency preferences. In this respect, we performed the Spearman's rank-order correlation test to measure the strength and direction of association between the most important PTdeterring factors in each period and the PT use variables of Table 2 (since all these variables are ordinal). Regarding the profile characteristics (Table 3), we selected: (a) the Spearman's rank-order correlation test to explore whether the ordinal variables of age, residential area and income are correlated with the importance levels of the PT-discouraging factors, (b) the Kruskal-Wallis $H$-test to investigate whether the importance levels of the PT-discouraging factors are significantly differed among the groups of occupation and (c) the Mann-Whitney $U$-test to investigate whether the importance levels of the PT-discouraging factors are significantly differed among male and female users. For the Spearman's rank-order correlation analysis, the null hypothesis $\left(\mathrm{H}_{0}\right)$ was indicating that there is no relationship between profile/ PT trip frequency variables and the importance attributed to the critical PT-deterring factors. The alternative hypothesis $\left(\mathrm{H}_{1}\right)$ proposed that there is a statistically significant association between them. In the same manner, for the Kruskal-Wallis $H$-test and Mann-Whitney $U$-test, the null hypothesis $\left(\mathrm{H}_{0}\right)$ indicates that the population medians for occupation and gender are equal, while the $\mathrm{H}_{1}$ hypothesis proposes that they are not equal. We rejected the $\mathrm{H}_{0}$ hypotheses for $p$-values smaller than 0.05. All calculations were performed with the SPSS software [33].

\section{RESULTS AND DISCUSSION}

\subsection{Importance of PT-deterring factors}

Figures 3 and 4 show the relative importance that was attributed to each of the ten factors of Table 1 by the survey's participants.

In Figure 3, after lockdown, the most important reason that discouraged PT use in Sicily was the 'Decrease of PT scheduled services'. More than half of the respondents $(51.3 \%)$ highlighted factor $\mathrm{C}$ as the most important one, while $77.7 \%$ of them included it in their personal top-3 list. This is probably reasonable since factor $\mathrm{C}$ indicates the actual modifications in the temporal availability of PT services, which apparently led travellers to select other trip modes to fulfil their travel needs. Considerable importance has also been reported for factor G: 'Inadequate or out-of-date information for PT services', since almost 1 out of 4 PT travellers (24.9\%) underlined the primary role of accurate and updated information on 


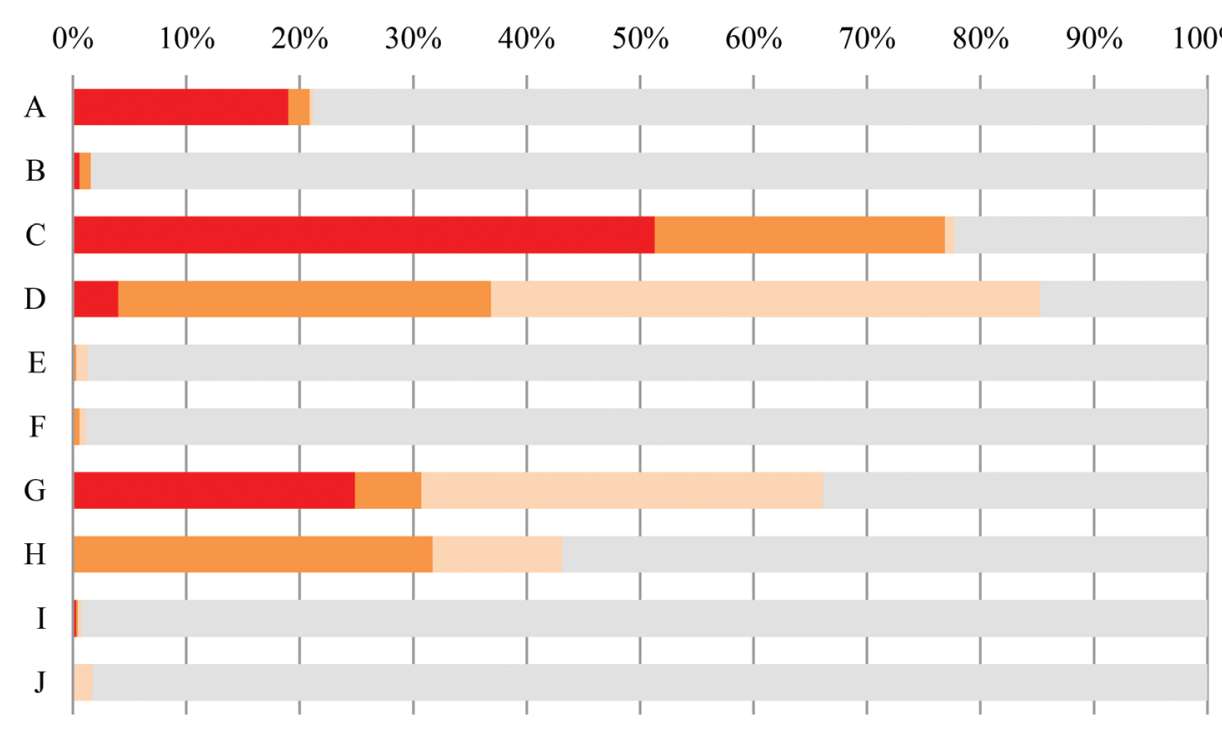

- First Most Important $\square$ Second Most Important $\square$ Third Most Important $₫$ Less Important

Figure 3: Importance rankings of the potential factors, which reduced PT demand in Sicily after the lockdown period.

PT services during the post-lockdown period. Along with $\mathrm{C}$ and $\mathrm{G}$ factors, the PT users in Sicily have also indicated the relatively great importance of factors A: 'Excess of maximum recommended capacity in PT buses' (21.1\% total importance score), D: 'Higher possibility of COVID-19 infection during PT use' (85.3\%) and H: 'General restrictions on PT services imposed by PT agencies' $(66.1 \%)$. These findings demonstrate that, after lockdown, travellers in Sicily reduced their PT trips due to factors that: (a) have been imposed as COVID-19 protection measures by local PT agencies or national/regional authorities ( $\mathrm{C}$ and $\mathrm{H}$ factors), (b) reflect the potential weaknesses of local PT agencies to quickly adapt to the new regime of operations (A and $\mathrm{G}$ factors) and (c) reveal a general hesitation to travel by PT due to the fear of getting infected with SARS-CoV-2. The remaining four factors, i.e. B, E, F and I, were not considered to be significant reasons for reducing PT trips after lockdown. In the case of B and F, PT passengers might have found that both sanitation of PT vehicles/premises and e-ticketing options have been applied properly in the local PT system without constituting any deterrent in its use. Additionally, both mass media information (E) and modified working hours or teleworking (I) did not seem to have influenced the perceptions of travellers regarding the use of PT after lockdown.

Figure 4 presents the same analysis for the Phase II period. While factor C: 'Decrease of PT scheduled services' remains as the most important reason among participants, the second most important one is now factor I: 'Modified business/working hours or/and teleworking', which has not been sufficiently underlined in the post-lockdown period. The combined consideration of factors $\mathrm{C}$ and I show that, during the Phase II period, travellers in Sicily probably faced difficulties in resuming their PT trips due to the potential mismatch between PT timetables and requirements emerged by the modified framework of business activities and working hours. 


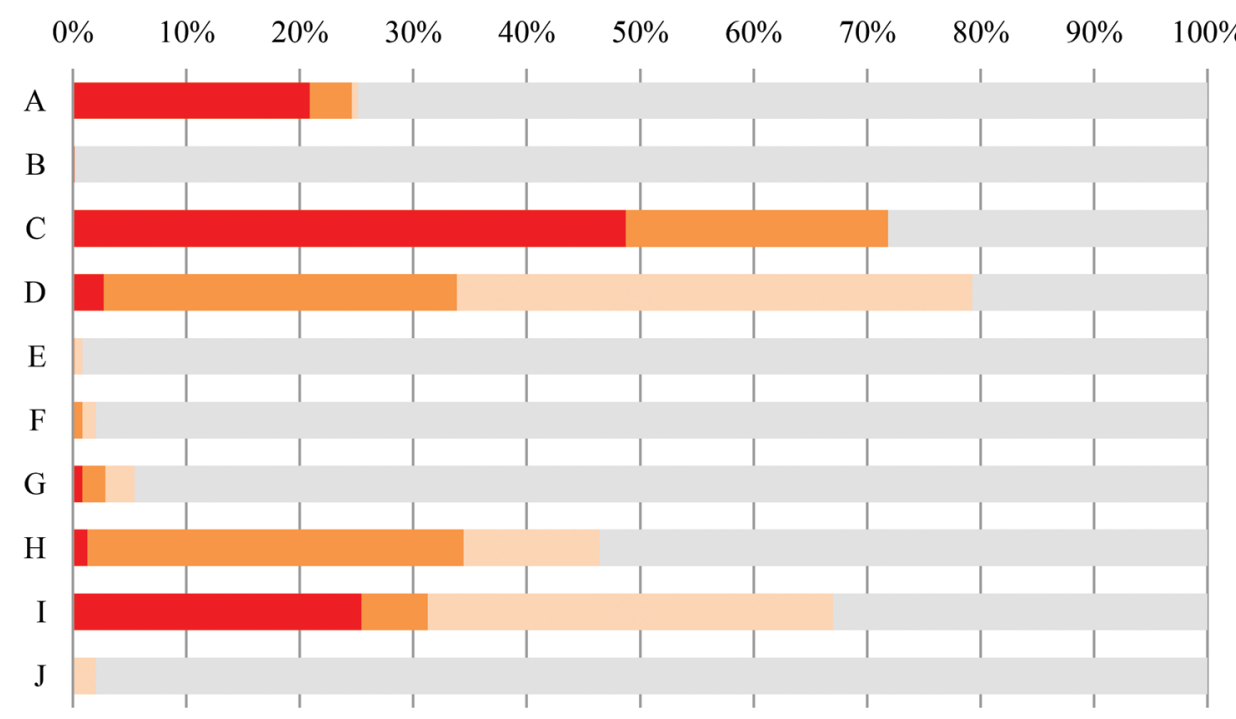

m First Most Important $\llbracket$ Second Most Important $₫$ Third Most Important $₫$ Less Important

Figure 4: Importance rankings of the potential factors that reduced PT demand in Sicily in the Phase II period.

Factors A, D and H continue to be regarded as important reasons in the Phase II period as well. PT users have not stopped fearing infection during PT use (D), while the restrictions of PT agencies $(\mathrm{H})$ and the limited capacity availability of services $(\mathrm{A})$ are still reasons to avoid PT. In Phase II, factor G: 'Inadequate or out-of-date information for PT services' is comparatively less important than in the post-lockdown period. This may imply that the information provision mechanisms of the local PT agencies have been improved and thus they do not place any important obstacle for PT use.

\subsection{Relationship with profile and PT trip frequency characteristics}

Tables 4 and 5 report the Spearman's rank-order correlation coefficients that indicate the strength, the direction and the statistical significance of any association existing between the most important PT-avoiding factors (as these were determined in Figures 3 and 4) and the sociodemographic and PT demand variables of the survey respondents during the post-lockdown and Phase II periods, respectively. In Table 4, all correlation coefficients have very low values, and none of them is statistically significant. Table 5 indicates a similar trend, though that for one variable, i.e. the 'Trip frequency with regional PT bus for Home-based Other purposes', there are two statistically significant correlations with factors $\mathrm{A}$ and $\mathrm{C}$, which, however, indicate very weak relationships $\left(r_{\mathrm{s}}<0.4\right)$.

For the rest of the sociodemographic variables of Table 3, we also obtained similar results. Specifically, the Kruskal-Wallis $H$-test and Mann-Whitney $U$-test indicated no statistically significant differences on the importance levels of PT-discouraging factors within the occupation and gender groups of the respondents. 
Table 4: Spearman's rank-order correlation coefficients $\left(r_{s}\right)$ between PT-discouraging factors and profile/PT trip characteristics in Sicily after the COVID-19 lockdown.

\begin{tabular}{lrrrrr}
\hline \multirow{2}{*}{$\begin{array}{l}\text { Sociodemographic and PT Demand } \\
\text { Variables }\end{array}$} & \multicolumn{6}{c}{$\begin{array}{l}\text { Important Discouraging Factors for PT Use } \\
\text { in Sicily After Lockdown }\end{array}$} \\
\cline { 2 - 7 } & A & C & D & G & \multicolumn{1}{l}{ H } \\
\hline Age & -0.034 & 0.020 & -0.005 & -0.003 & 0.003 \\
Residential Area & 0.013 & -0.015 & -0.037 & 0.000 & 0.008 \\
Household Monthly Income & 0.013 & -0.008 & -0.020 & 0.004 & 0.004 \\
Trip Frequency With Local PT Bus for & 0.003 & -0.003 & 0.021 & 0.044 & -0.048 \\
Home-Based Work Purposes & & & & & \\
$\begin{array}{l}\text { Trip Frequency With Local PT Bus for } \\
\text { Home-Based Other Purposes }\end{array}$ & -0.028 & 0.022 & -0.052 & 0.045 & 0.003 \\
$\begin{array}{l}\text { Trip Frequency With Regional PT Bus for } \\
\text { Home-Based Work Purposes }\end{array}$ & -0.002 & 0.015 & 0.011 & 0.028 & -0.033 \\
$\begin{array}{l}\text { Trip Frequency With Regional PT Bus for } \\
\text { Home-Based Other Purposes }\end{array}$ & -0.020 & 0.023 & -0.053 & 0.033 & 0.014 \\
\hline
\end{tabular}

Table 5: Spearman's rank-order correlation coefficients $\left(r_{\mathrm{s}}\right)$ between PT discouraging factors and profile/PT trip characteristics in Sicily during Phase II.

\begin{tabular}{lrrrrrr}
\hline \multirow{2}{*}{$\begin{array}{l}\text { Sociodemographic and PT Demand } \\
\text { Variables }\end{array}$} & \multicolumn{6}{c}{ Important Discouraging Factors for PT Use in } \\
\cline { 2 - 7 } & A & C & D & H & \multicolumn{1}{c}{ I } \\
\hline Age & 0.023 & -0.027 & -0.027 & -0.011 & 0.008 \\
Residential Area & -0.061 & 0.037 & -0.005 & 0.054 & -0.003 \\
Household Monthly Income & 0.058 & -0.023 & -0.058 & -0.014 & 0.009 \\
Trip Frequency With Local PT Bus for & 0.002 & 0.002 & 0.039 & 0.018 & -0.017 \\
Home-Based Work Purposes & & & & & \\
Trip Frequency With Local PT Bus for & 0.022 & 0.042 & 0.041 & -0.010 & -0.048 \\
Home-Based Other Purposes & & & & & \\
Trip Frequency With Regional PT Bus & -0.011 & 0.019 & 0.024 & 0.010 & -0.016 \\
for Home-Based Work Purposes & & & & & \\
$\begin{array}{l}\text { Trip Frequency With Regional PT Bus } \\
\text { for Home-Based Other Purposes }\end{array}$ & $-0.138^{* *}$ & $0.145^{* *}$ & -0.034 & 0.022 & 0.014 \\
\hline
\end{tabular}

**Correlation is significant at the 0.01 level.

Overall, these findings demonstrate that the importance ratings of PT travellers do not vary due to their profile and PT trip frequency characteristics. It seems that there is a kind of general agreement among survey participants regarding the factors that are particularly responsible for the reduced PT demand trends during the two examined pandemic periods. 


\section{CONCLUSION}

The COVID-19 crisis and its implications at different time scales have been characterized by numerous impacts on travel behaviour, i.e. modal choices and habits. This research has attempted to identify the factors that led to a significant PT demand reduction in Sicily during two different periods of COVID-19 pandemic and associate them with sociodemographic characteristics and travel behaviour variables. Empirical findings indicated that the modifications of PT temporal and capacity availability service levels (i.e. the decrease of scheduled PT services and the limitations on the maximum people on board) have been important discouraging factors for PT use in Sicily after the COVID-19 lockdown period. Along with them, we recognized that the PT demand reduction may also be attributed to the general fear of being infected by COVID-19 when travelling by PT buses, as well as to the teleworking/modified business hour environment, which apparently was not sufficiently treated by a corresponding adjustment of the PT services in Sicily. These PT-deterring factors were not found to be significantly differentiated among the various sociodemographic groups of travellers who were examined.

Reconfiguration of travel behaviour will be an emerging area of research. It is important to understand how and why restrictions have affected and will continue to affect different social groups, causing in some cases social, gender, age and spatial imbalances and in other cases a reduction in the connectivity of certain areas of the cities. Experience from previous SARS pandemics around the world (e.g. Southeast Asia) could perhaps help formulate best practices and recommended social responses. The drastic reduction in PT use could become a widespread trend and cause some segments of the population to be excluded from travel such as low-income workers and could potentially affect their mental health as well. The reduction in PT choice could also promote the purchase of private vehicles increasing congestion on the roads. This research lays the groundwork for a better implementation of urban planning processes in the post-pandemic period, favouring the analysis of different types of potential users, citizens or commuters.

\section{REFERENCES}

[1] Moslem, S., Campisi, T., Szmelter-Jarosz, A., Duleba, S., Nahiduzzaman, K. M. \& Tesoriere, G., Best-worst method for modelling mobility choice after COVID-19: evidence from Italy. Sustainability, 12(17), p. 6824, 2020.

[2] Moraci, F., Errigo, M. F., Fazia, C., Campisi, T. \& Castelli, F., Cities under pressure: Strategies and tools to face climate change and pandemic. Sustainability, 12(18), p. 7743, 2020.

[3] Politis, I., Georgiadis, G., Papadopoulos, E., Fyrogenis, I., Nikolaidou, A., Kopsacheilis, A., Sdoukopoulos, A. \& Verani, E., COVID-19 lockdown measures and travel behavior: the case of Thessaloniki, Greece. Transportation Research Interdisciplinary Perspectives, 10, p. 100345, 2021.

[4] Campisi, T., Basbas, S., Skoufas, A., Akgün, N., Ticali, D. \& Tesoriere, G., The impact of COVID-19 pandemic on the resilience of sustainable mobility in Sicily. Sustainability, 12(21), p. 8829, 2020.

[5] Okubo, T., Inoue, A. \& Sekijima, K., Teleworker performance in the COVID-19 era in Japan. Asian Economic Papers, 20(2), pp. 175-192, 2021.

[6] Belzunegui-Eraso, A. \& Erro-Garcés, A., Teleworking in the context of the Covid-19 crisis. Sustainability, 12(9), p. 3662, 2020. 
[7] Campisi, T., Acampa, G., Marino, G. \& Tesoriere, G., Cycling master plans in Italy: The I-BIM feasibility tool for cost and safety assessments. Sustainability, 12(11), p. 4723, 2020.

[8] Kraus, S. \& Koch, N, Provisional COVID-19 infrastructure induces large, rapid increases in cycling. Proceedings of the National Academy of Sciences, 118(15), 2021. https://doi.org/10.1073/pnas.2024399118.

[9] Tarasi, D., Daras, T., Tournaki, S. \& Tsoutsos T., Transportation in the Mediterranean the COVID-19 pandemic era. Global Transitions, 3, pp. 55-71, 2021.

[10] De Vos, J., The effect of COVID-19 and subsequent social distancing on travel behavior. Transportation Research Interdisciplinary Perspectives, 5, p. 100121, 2020.

[11] Wielechowski, M., Czech, K. \& Grzęda, Ł., Decline in mobility: public transport in Poland in the time of the COVID-19 pandemic. Economies, 8(4), p. 78, 2020.

[12] Eisenmann, C., Nobis, C., Kolarova, V., Lenz, B. \& Winkler, C., Transport mode use during the COVID-19 lockdown period in Germany: The car became more important, public transport lost ground. Transport Policy, 103, pp. 60-67, 2021.

[13] Basbas, S., Georgiadis, G., Campisi, T. \& Tesoriere, G., Factors influencing public transport demand in Sicily during COVID-19 era: a study of commuters' travel and mode choice behaviors, Computational Science and Its Applications - ICCSA 2021. Lecture Notes in Computer Science, Vol. 12954, eds. O. Gervasi et al., Springer, Cham, 2021. https://doi.org/10.1007/978-3-030-86979-3_25

[14] Gutiérrez, A., Miravet, D. \& Domènech, A., COVID-19 and urban public transport services: emerging challenges and research agenda. Cities \& Health, pp. 1-4, 2020. DOI: https://doi.org/10.1080/23748834.2020.1804291.

[15] Di Carlo, P., Chiacchiaretta, P., Sinjari, B., Aruffo, E., Stuppia, L., De Laurenzi, V., Di Tomo, P., Pelusi, L., Potenza, F., Veronese, A., Vecchiet, J., Falasca, K. \& Ucciferri, C., Air and surface measurements of SARS-CoV-2 inside a bus during normal operation. Plos One, 15(11), p. e0235943, 2020. https://doi.org/10.1371/journal.pone.0235943.

[16] Crowley, F., Daly, H., Doran, J. \& Ryan, G., COVID-19, social distancing, remote work and transport choice. SRERC Working Paper Series, (No. SRERCWP2020-4), 2020.

[17] Lupton, D. \& Willis, K., (eds), The COVID-19 Crisis: Social Perspectives, Routledge, pp. 14-24, 2021.

[18] Jenelius, E. \& Cebecauer, M., Impacts of COVID-19 on public transport ridership in Sweden: Analysis of ticket validations, sales and passenger counts. Transportation Research Interdisciplinary Perspectives, 8, p. 100242, 2020

[19] Campisi, T., Basbas, S., Al-Rashid, M. A., Tesoriere, G. \& Georgiadis, G., A regionwide survey on emotional and psychological impacts of COVID-19 on public transport choices in Sicily, Italy. Transactions on Transport Sciences, 2, 2021. DOI: 10.5507/ tots.2021.010.

[20] Gkiotsalitis, K. \& Cats, O., Public transport planning adaption under the COVID-19 pandemic crisis: literature review of research needs and directions. Transport Reviews, 41(3), pp. 374-392, 2021.

[21] Politis, I., Georgiadis, G., Nikolaidou, A., Kopsacheilis, A., Fyrogenis, I., Sdoukopoulos, A., Verani, E. \& Papadopoulos, E., Mapping travel behavior changes during the COVID-19 lock-down: a socioeconomic analysis in Greece. European Transport Research Review, 13(21), 2021. DOI: https://doi.org/10.1186/s12544-021-00481-7. 
[22] Rasca, S., Markvica, K. \& Ivanschitz, B.P., Impacts of COVID-19 and pandemic control measures on public transport ridership in European urban areas-The cases of Vienna, Innsbruck, Oslo, and Agder. Transportation Research Interdisciplinary Perspectives, 10, p. 100376, 2021.

[23] Eisenmann, C., Nobis, C., Kolarova, V., Lenz, B. \& Winkler, C., Transport mode use during the COVID-19 lockdown period in Germany: the car became more important, public transport lost ground. Transport Policy, 103, pp. 60-67, 2021.

[24] Shen, J., Duan, H., Zhang, B., Wang, J., Ji, J.S., Wang, J., Pan, L., Wang, X., Zhao, K., Ying, B., Tang, S., Zhang, J., Liang, C., Sun, H., Lv, Y., Li, Y., Li, T., Li, L., Liu, H., Zhang, L., Wang, L. \& Xiaoming Shi, X., Prevention and control of COVID-19 in public transportation: experience from China. Environ. Pollution, 266 (2), p. 15291, 2020.

[25] Dzisi, E.K.J. \& Dei, O.A., Adherence to social distancing and wearing of masks within public transportation during the COVID 19 pandemic. Transportation Research Interdisciplinary Perspectives, 7, p. 100191, 2020.

[26] Interreg Europe, Making Public Transport Safe in Time of COVID-19, Interreg Europe, available at, https://www.interregeurope.eu/policylearning/news/9216/making-publictransport-safe-in-times-of-covid-19/ (accessed 31 August 2021).

[27] Glodeanu, A., Gullón, P. \& Bilal, U., Social inequalities in mobility during and following the COVID-19 associated lockdown of the Madrid metropolitan area in Spain. Health \& Place, 70, p. 102580, 2021.

[28] Mills, G., Cullen, W., Moore, N. \& Foley, R., Making sense of publicly available data on COVID-19 in Ireland. medRxiv, 2020.

[29] Mantu, S., EU Citizenship, Free Movement, and Covid-19 in Romania. Frontiers in Human Dynamics, 2:594987, 2020. https://doi.org/10.3389/fhumd.2020.594987.

[30] Oh, J., Lee, H.Y., Long, K.Q., Markuns, J.F., Bullen, C., Artaza Barrios, O. E., Hwang, S., Seo, Y.S., McCool, J., Kachur, S. P., Chan, C.C., Kwon, S., Kondo, N., Minh, H.V., Moon, J. R., Rostila, M., Norheim, O.F., You, M., Withers, M., Lil, M., Lee, E.J., Benski, C., Park, S.K., Nam, E.W., Gottschalk, K., Kavanagh, M.M., Lee, J.K., McKee, M., Subramanian, S. V. \& Gostin, L.O., How well does societal mobility restriction help control the COVID-19 pandemic? Evidence from real-time evaluation. Available at SSRN: https://ssrn.com/abstract=3706748. Accessed on: 10 Mar. 2020. http://dx.doi. org/10.2139/ssrn.3706748.

[31] Galeazzi, A., Cinelli, M., Bonaccorsi, G., Pierri, F., Schmidt, A.L., Scala, A., Pammolli, F. \& Quattrociocchi, W., Human mobility in response to COVID-19 in France, Italy and UK. Scientific Reports, 11(1), pp. 1 -10, 2021. https://doi.org/10.1038/s41598-02192399-2.

[32] Van Der Drift, S., Wismans, L. \& Olde Kalter, M.J., Changing mobility patterns in the Netherlands during COVID-19 outbreak. Journal of Location Based Services, pp. 1-24, 2021. DOI: https://doi.org/10.1080/17489725.2021.1876259.

[33] IBM Corp., Released. IBM SPSS Statistics for Windows, Version 25.0, IBM Corp., Armonk, NY, 2017. 